\title{
The validity of using morphological characteristics as predictors of age in the kelp Pterygophora californica (Laminariales, Phaeophyta)
}

\author{
Zachary P. Hymanson*, Daniel C. Reed ${ }^{* *}$, Michael S. Foster, John W. Carter***
}

Moss Landing Marine Laboratories, PO Box 450, Moss Landing, California 95039, USA

\begin{abstract}
Previous studies have used stipe ring counts to estimate the age of several species in the Laminariales. Although this method is widely accepted, it has rarely been validated. To test the validity of aging Pterygophora californica by counting rings formed in the stipe, we sampled plants of known age between 1.0 and $4.4 \mathrm{yr}$ old and plants with a calculated age of $12 \mathrm{yr}$. For a given cohort, the number of complete rings closely approximated the known age in years, indicating ring counts are a reliable method for estimating the age structure of $P$. californica populations. However, ring counts from individual plants of known age can vary by $\pm 2 \mathrm{yr}(95 \% \mathrm{CI})$, and among readers counting the same plants by \pm 1 yr $(95 \%$ CI). Single plants, therefore, could not be reliably aged by ring counts. Linear relationships between 2 morphometric measures (stipe length and stipe diameter) and number of rings varied both within and between stands and sites, suggesting these measures are not reliable for estimating the age of this alga in the areas sampled. Stand density may be an important factor contributing to the variation in these morphometric measures. Short-term ( $22 \mathrm{wk}$ ) field manipulations of stand density showed that plants at high density 130 plants $\mathrm{m}^{-2}$ grew faster in stipe length and slower in stipe diameter than those at medium $\left(6\right.$ plants $\left.\mathrm{m}^{-2}\right)$ and low $\left(2\right.$ plants $\left.\mathrm{m}^{-2}\right)$ densities. Plants collected in a multi-site survey, however, showed no relationship between stand density and stipe morphology. indicating factors other than density also influence stipe growth. Short-term (22 wk) field manipulations, which reduced ambient light levels by up to $58 \%$, had no significant effects on stipe morphology.
\end{abstract}

\section{INTRODUCTION}

One of the great difficulties in ecology is determining the appropriate time scales over which to examine processes or events that influence the structure of natural populations. There is an increasing awareness that existing structure may reflect prior events and processes as well as present ones (Sousa 1984, Pickett \& White 1985). Unfortunately, the immediate and longterm consequences of past events on present structure are frequently unknown. The significance of these past events, however, may be interpreted in part from the age structure of present populations (reviewed in

Present addresses:

- Department of Water Resources, Central District, $3251 \mathrm{~S}$ Street, Sacramento, California 95816, USA

- Marine Science Institute, University of California, Santa Barbara, California 93106, USA

-.. Lockheed Aeronautical Systems Company, PO Box 33. Dept 1-308, Ontario, California 91762, USA
Harper 1977. Canham \& Marks 1985, Veblen 1985, and Bazzaz 1983). Information on life span and replacement rates of populations is also essential in determining population stability and changes in state (Connell \& Sousa 1983). Thus, the ability to age individuals and populations is critical to our understanding of population dynamics, and has been a necessary tool for investigating the ecology of a wide variety of organisms (Morris 1972, Fritts 1976, Ekaratne \& Crisp 1982, Cailliet et al. 1986, Ebert 1988)

Aging techniques usually involve the examination of structures that periodically but regularly vary in morphology. In some perennial marine algae, the cells in the secondary cortex of the stipe differ in structure and/ or contents on a recurring basis, resulting in the formation of rings, which have been used to estimate age (Frye 1918, Parke 1948, Hayashida 1977, Kain 1979. Novaczek 1981, Dayton et al. 1984, De Wreede 1984, Klinger \& De Wreede 1988). Ring formation in the stipitate kelp Pterygophora californica, as with other Laminariales studied, is due to repeated alterations in 
cortical cell size and contents resulting in the formation of light and dark bands (Mac Millian 1902, Smith 1939). These cellular differences, hereafter referred to as light zones and (dark) rings, are thought to be due to variations in plant growth rates: the smaller cells of dark rings being produced during periods of slow growth. and the larger cells of light zones being produced during periods of fast growth (Mac Millian 1902, Parke 1948, Kain 1963, 1979, John 1969).

Frye (1918) was one of the first to propose that stipe rings could be used for age determination. He suggested that the understory kelp Pterygophora californica produced the same number of sporophylls each year: thus, the age of any individual could be determined by dividing the total number of sporophylls and sporophyll scars by the number of sporophylls on a 1yr-old plant. To test the hypothesis that rings were formed annually, Frye compared the age by sporophyll count to the age by ring count in 7 individuals and, along with other qualitative observations, concluded that 1 dark ring was added per year. However, Frye did not test the assumption that sporophyll production rate was constant, so neither ring counts nor the other qualitative observations were truely validated. Nevertheless, his suggestion that rings are formed annually has been widely accepted (Rigg \& Miller 1949, Lobban 1978. Druehl 1981, Dayton et al. 1984, De Wreede 1984).

Dayton et al. (1984) used the frequency distribution of the number of stipe rings to determine the age class structure of Pterygophora californica in a southern California kelp forest. They found that the mode of the frequency distribution increased linearly with time, and concluded that the stipe rings were annual. The relationship between number of rings and age was not validated.

De Wreede (1984) measured the yearly stipe elongation rate of tagged Pterygophora californica, and determined the ratio of stipe length to ring number in untagged plants from 3 shallow subtidal sites. The ratio results were found to closely approximate the annual elongation rate, and combined with the age validation of small plants ( $\leq 25 \mathrm{~cm}, 1$ to $2 \mathrm{yr}$ old), he concluded that 1 light zone and dark ring was formed each year. The use of rings for aging plants older than 2 yr, however, was not validated.

Even if validated, aging solely by ring counts may not always be an acceptable method since plants must be sacrificed to be aged, and counts cannot be readily performed in situ. Small (1 $\mathrm{mm}$ diameter) coring devices can be used to extract cortical tissue for counting, but even this small amount of damage causes the stipes to break during storms (Foster pers. obs.). An aging method based on some external measure such as stipe length or stipe diameter could prove superior, being easily performed in situ, and reducing the need to sacrifice plants. De Wreede $(1984,1986)$ recognized the benefits of using an external measure to estimate plant age. He found a linear correlation between stipe length and ring number for samples of Pterygophora californica from 2 populations, and a slightly curvilinear correlation for a third. He then used these statistical relationships to estimate the age structure of the populations from their stipe length distributions. However, estimating plant age from stipe length measurements may be questionable since it is unlikely that stipe elongation remains constant throughout an individual's life.

Ultimately, any aging method should be tested on several geographically distinct populations before drawing conclusions about the species as a whole. Testing the validity of an aging method using several populations is important since both individual and environmental variability can influence the results. Although the effects of individual variability can be reduced by proper sampling design, environmental variability is not always so easily controlled. Exposure, plant density, and seasonal variation in nutrients, light, and weather all have the potential of influencing kelp growth. Novacezk (1981) found that the growth and ring structure of Ecklonia radiata were influenced by both depth and wave exposure, so that only in certain individuals (the long-stiped variety) did the number of rings corresponded to the age in years. Klinger \& De Wreede (1988) found that variation between sites in Laminaria setchellii (Silva) growth made it difficult to predict age from plant size.

In this study we used individuals from several known age classes to investigate the validity of using stipe ring counts as a measure of age in Pterygophora californica. To determine if external morphometric characteristics could be used to age individuals of this species, we examined the relationships between ring number, and stipe length and diameter for 3 different populations. To begin to understand how the environment affects the growth and morphology of $P$. californica, the effects of plant density and bottom irradiance were assessed in a short-term field experiment. Lastly, morphometric measurements and density estimates of several $P$. californica populations occurring along the California coast were made to determine if the effects of density on plant morphology were consistent between geographically distinct populations.

\section{METHODS}

Pterygophora californica is a perennial brown alga in the order Laminariales. It occurs subtidally from British Columbia into Baja California (Abbott \& Hollenberg 
1976). The diploid sporophyte is composed of a holdfast, an erect woody stipe, a terminal vegetative blade, and lateral sporophylls (Fig. 1). The holdfast and stipe are perennial (Abbott \& Hollenberg 1976), while the size and number of blades varies both seasonally and annually (Canestro 1987, Reed 1989). Growth in length is initiated by an intercalary meristem located between the stipe and terminal blade (Smith 1939). Sporophylls arise from lateral buds of meristematic tissue, and growth in stipe diameter is initiated by a meristoderm lying just under the epidermis of the stipe (Smith 1939). The plant is often abundant, and its growth and population dynamics have been of considerable interest (e.g. Dayton et al. 1984, Reed \& Foster 1984, De Wreede 1984, 1986).

Age verification. The age verification work was done at Stillwater Cove, Carmel Bay, California (Fig. 2; see Foster 1982, Reed \& Foster 1984 for further site descriptions). In spring 1978, 1980, and 1982 sporophytes that recruited to experimental openings in the existing Pterygophora californica canopy at $15 \mathrm{~m}$ depth were tagged when 5 to $10 \mathrm{~cm}$ tall. Tags consisted of labels attached to the stipes with nylon cable ties, as well as duplicate labels secured to the rock next to the holdfast with nails. Although a few months old (assuming fertilization = day zero), these individuals were considered to be age zero when tagged. Eleven individuals that

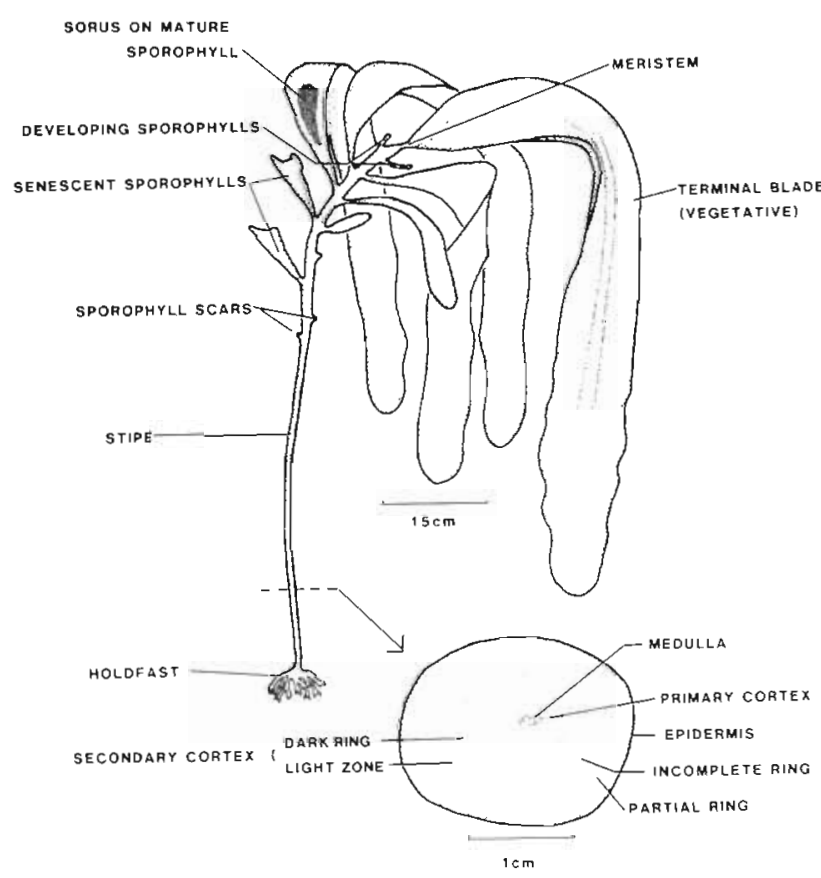

Fig. 1. Pterygophora californica (after Dawson \& Foster 1982) and a typical cross section of a 3.5-yr-old plant magnified $60 \times$ recruited in May 1978 were harvested in October 1982 (known age $=4.4 \mathrm{yr}$ ) 10 recruits from March 1980 were harvested in October 1982 (known age $=2.6 \mathrm{yr}$ ); and 18 recruits from May 1982 were harvested in May 1983 (known age $=1.0 \mathrm{yr}$ ).

To determine the reliability of ring counts in estimating the age of older and larger individuals, we counted the rings in 10 plants collected from a single stand at Stillwater Cove in May 1987. Data on the mean size of these plants in February 1980, combined with estimates of the growth rates to these sizes from the known aged plants, suggested these plants recruited no later than 1975.

At Stillwater Cove new recruits first appear in the spring (observed to be the time of fastest growth; Reed \& Foster 1984, Canestro 1987). Examination of numerous plants showed that a light zone was the first to form in the secondary cortex, suggesting light zones are laid down during periods of fast growth. A dark ring is subsequently formed, most likely during the ensuing period of slow growth (beginning in late fall at Stillwater Cove). Thus, we presumed 1 light zone and 1 dark ring are formed during each year. In estimating age from ring counts, dark rings were counted as 1 complete year. If a relatively narrow light zone occurred at the edge of a stipe, it was counted as 1 half-year.

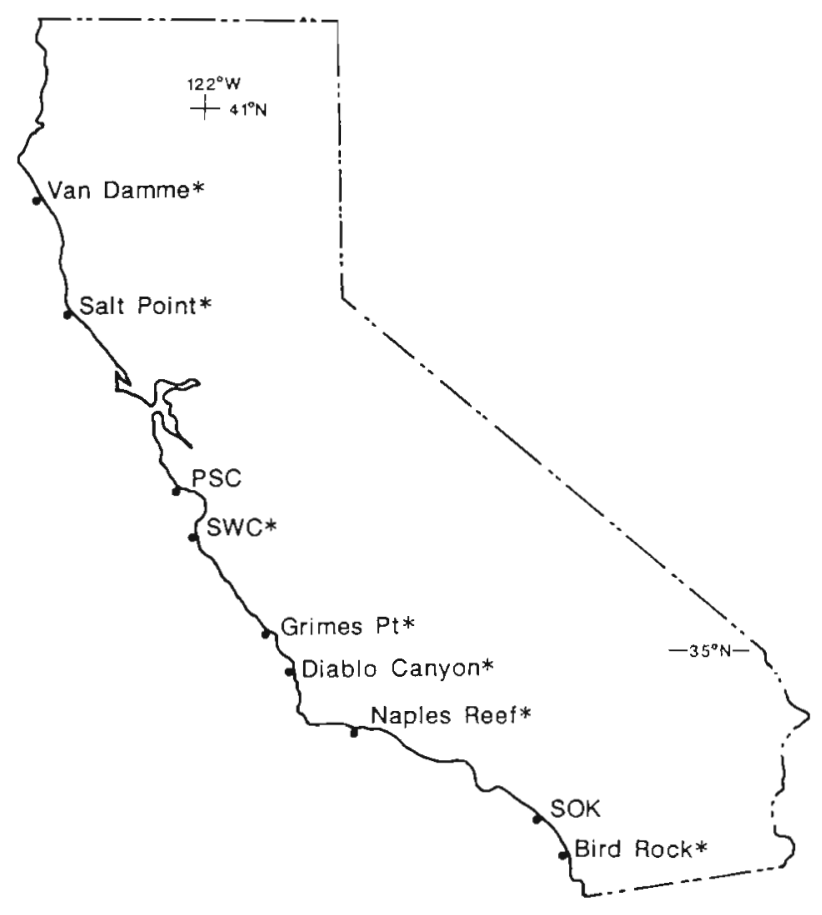

Fig. 2. California, USA. Locations of the sites sampled in the age and growth study and the multi-site survey. SWC: Stillwater Cove; PSC: Point Santa Cruz; SOK: San Onofre Kelp Forest. "Sites sampled in the multi-site survey 
To count rings, a cross section of the stipe was made 5 to $10 \mathrm{~cm}$ above the base of the haptera (Fig 1). Our observations indicated that recruits unshaded by adults grow at least $10 \mathrm{~cm}$ tall in $3 \mathrm{mo}$; thus, all rings produced would be counted in a cross section less than or equal to $10 \mathrm{~cm}$ above the holdfast. The surface of this basal cross section was sanded smooth with 650 grit wet/dry sandpaper, and counts were made directly from this surface under a strong light with an unaided eye. Only rings that completely circled the stipe were counted. Stipe rings were counted independently by at least 2 people. Means of these counts were used in a linear regression of known age versus number of rings to interpret the validity of estimating the age of Pterygophora californica from stipe ring counts.

De Wreede (1984) found a clear separation of rings in the stipes of Pterygophora californica from British Columbia. However, the rings of plants from Stillwater Cove and other California populations did not, in general, show such a distinct pattern. Each stipe examined was unique in the number and pattern of rings, and stipes were often asymmetrical in shape (Fig. 1). Incomplete rings (Fig. 1) were also quite common, but not counted because they displayed no consistent pattern among plants from the same population. Although used by Kain (1963) and Novaczek (1981), ring counts made from longitudinal sections of the stipe were more difficult to interpret and were used only rarely to corroborate counts from cross sections.

Age determination using morphometric characteristics. In addition to variation with age, stipe morphology often varies with location in this kelp (pers. obs.). We examined the relationship between number of rings and morphology using randomly collected plants from 4 stands located at 3 different sites (SWC: Stillwater Cove; PSC: Point Santa Cruz; and SOK: San Onofre Kelp Forest; Fig. 2). Data were collected from 2 different stands at Stillwater Cove. One of these stands (SWC-2) was also used in the age verification study (see above). The other stand (SWC-1) was about $200 \mathrm{~m}$ inshore at $10 \mathrm{~m}$ depth. Point Santa Cruz, located at the northern end of Monterey Bay, is described in Pearse \& Hines (1979). The most southern site, San Onofre Kelp Forest, is described in Dean \& Jacobsen (1984) and Dean et al. (1984).

Data collected on stipe morphology consisted of measurements of stipe length and diameter. Stipe length was defined as the distance from the base of the haptera to the transition zone between the stipe and the terminal blade (Fig. 1). Stipe diameter was measured as the greatest stipe width $10 \mathrm{~cm}$ above the base of the haptera. Ring counts were made as described above ('Age verification') except average counts from SOK plants were rounded to the nearest whole number. The relationships between stipe length, diameter, and ring number were examined across stands in an analysis of covariance (ANCOVA) where ring number was a function of both stand and the covariate (i.e. either stipe length or diameter; SAS 1985)

For the stipe length or diameter to be a good general predictor of age in this ANCOVA model, 3 conditions had to be met: (1) there had to be no significant effect of stand on ring number (i.e. similar $y$-intercepts for the regressions of ring number and the morphometric variable); (2) the relationship between ring number and the morphometric variable could not vary as a function of the stand (i.e. similar slopes for the regression lines as indicated by no significant interaction between stand and the morphometric variable); and (3) there had to be a high correlation between ring number and the morphometric variable, especially since it is a secondary correlation used to determine age.

An attempt was also made to include the total number of sporophylls (the number of existing sporophylls plus any sporophyll scars) as a morphometric measure. Frye (1918) reported variable success in estimating age in Pterygophora californica from the number of sporophylls and sporophyll scars. At our sites, however, sporophyll data were not useful because scars often faded or blended together, and older plants commonly had several sporophylls arising from the same point.

Environmental effects. To test the relationship between stand density and plant morphology, Pterygophora californica were transplanted to experimental racks at 3 different densities within Stillwater Cove in March 1985. Transplanted individuals were haphazardly selected from a stand of kelp that recruited in 1983-1984 (Canestro 1987). Initial stipe length of the transplants ranged from 13 to $60 \mathrm{~cm}$, and initial stipe diameter ranged from 18 to $25 \mathrm{~mm}$. Transplants were pried loose from the substrate and re-attached to experimental racks using rubber inner tubing. Holdfasts were inserted through slits in the tubing. Experimental racks were constructed of PVC pipe, and were anchored $20 \mathrm{~cm}$ above the bottom on concrete blocks placed at $7 \mathrm{~m}$ depth (see Hymanson 1986 for details).

Plants were transplanted to one of 3 experimental density treatments: 30 plants $\mathrm{m}^{-2}$ (high density), 6 plants $\mathrm{m}^{-2}$ (medium density), and 2 plants $\mathrm{m}^{-2}$ (low density). We have observed Pterygophora californica growing at all the above densities, and the medium density treatment is based on the mean density of plants at the collection site. In the medium density treatment, 6 experimental plants were attached to the inner portions of a $1 \mathrm{~m}^{2}$ rack, and 7 additional plants were attached around the perimeter (for a total of 13 plants) to ensure that all experimental plants were at the same relative density. In the low density treatment, 6 experimental plants were attached to the inner por- 
tions of a $9 \mathrm{~m}^{2}$ rack, and 12 additional plants were attached around the perimeter (for a total of 18 plants) to ensure that all experimental plants were at the same relative density. In the high density treatment, 30 plants were attached to a $1 \mathrm{~m}^{2}$ rack; experimental plants were randomly chosen from the subset of individuals not attached to the perimeter of the rack. Although plants in natural stands are often clumped, plants in all the density treatments were attached uniformly to standardize the effects of density on the individual. All density treatments had 2 replicates, and measurements were made on 6 plants in each replicate.

To examine the relationship between stand density and plant morphology over a broad geographic range, we sampled stands of Pterygophora californica at 7 sites along $1175 \mathrm{~km}$ of California coastline in August 1985 (see Fig. 2 for site locations). At each site mean stand density was estimated from 5 randomly placed $1 \mathrm{~m}^{2}$ quadrats. Within each stand 5 randomly selected plants were collected for stipe length and stipe diameter measurements, and stipe ring counts. This is a small sample size, but quadrats were located in patches of similar density within each stand. Data from the multisite survey were used in linear regressions of stipe length and stipe diameter versus stand density. These data were also used to calculate the ratio of mean stipe length to mean number of rings.

To test the effects of variation in bottom irradiance on stipe growth, we transplanted Pterygophora californica at the medium density to 4 additional racks in Stillwater Cove using the same methods described in the density experiment. Two of these racks were fitted with shades made of neutral density fiberglass screen mounted $1.3 \mathrm{~m}$ above the racks. These shades reduced the light level at depth by $58 \%$. This amount of reduction was greater than the amount of average light reduction $(46 \%)$ resulting from the subsurface canopy of adult $P$. californica growing at the collection area during this experiment. The remaining 2 racks had covers of $0.061 \mathrm{~cm}$ thick clear vinyl attached in the same manner as shades. These covers served as physical controls for shades. Weekly scrubbing or replacement of the shades and covers made fouling negligible. The 2 nearby medium density treatment racks also served as the open (not shaded or covered) treatment in the light experiment.

Instantaneous quantum irradiance over the photosynthetically active region (PAR) was measured just below the adult Pterygophora californica canopy at the collection area, and just above the plants of the various light treatments at the experimental area on 4 separate occasions. Irradiance (PAR) measurements were made with Li-Cor surface cosine and underwater spherical sensors (details in Hymanson 1986). After all plants of the density and light experiments were moved and tagged, initial measurements of stipe length and stipe diameter (as defined above) were made. These measurements were repeated 6 times over $22 \mathrm{wk}$. The results of both experiments were analyzed with fixed factor ANOVAs with replicate racks nested within either density or light treatments (Sokal \& Rohlf 1981).

\section{RESULTS}

\section{Age verification}

The slope of the regression line between known age and number of cortical rings in the stipe of Pterygophora californica was nearly 1, indicating rings are formed annually over the age intervals considered (Fig. 3). Although a high correlation was found between number of rings and known age $\left(r^{2}=0.92\right)$, ring counts of plants within an age group did vary (Fig. 3) The mean and standard deviations of the number of rings counted in the known age plants (in Fig. 3) were $1.0 \mathrm{yr}, 1.5 \pm 0.59 ; 2.6 \mathrm{yr}, 3.5 \pm 0.56$; and $4.4 \mathrm{yr}, 4.7 \pm$ 0.52 . Thus, if the rings of a single plant (from a known age population between 1 and $4.4 \mathrm{yr}$ old) were counted, the $95 \%$ confidence interval (CI) for the estimate of its correct age is about \pm 2 yr In addition, for 1 sample of 22 plants with between 2 and 8 rings, the mean difference in ring counts between readers was 0.95 rings $\pm 0.33(95 \% \mathrm{CI})$.

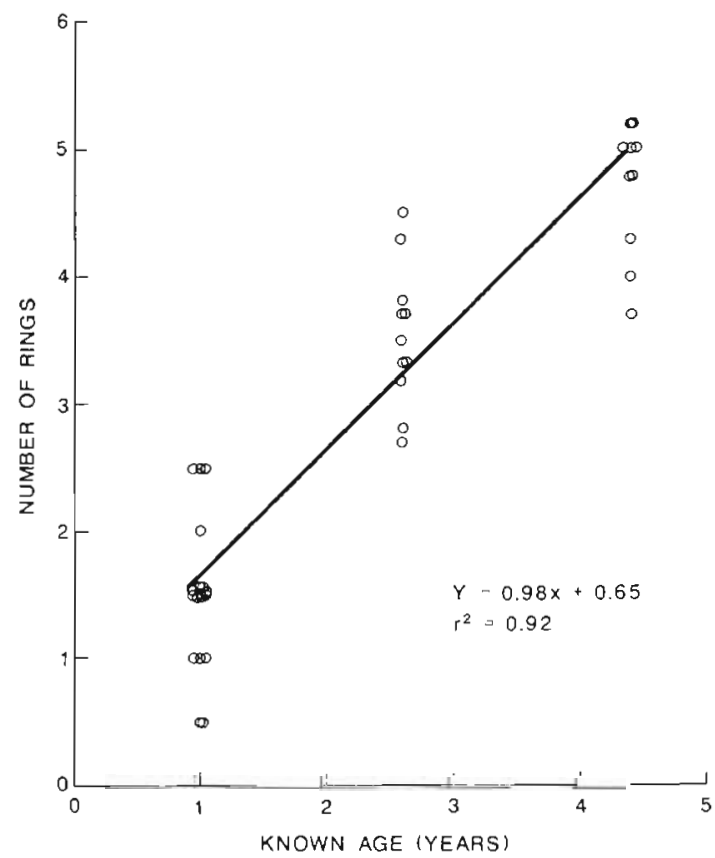

Fig. 3. Pterygophora californica. Relationship between number of rings and known age in years for plants from Stillwater Cove. See text for details of how ring counts were made. Overlapping points are offset 
The number of dark rings counted in the cross sections of the 10 larger plants ranged from 10.0 to 13.5 with a mean of $11.7 \pm 1.14$ (SE) The actual age of these plants was estimated from the length of time individuals of the stand were tagged (1980 to 1987), combined with their estimated age at the time of tagging. At the time of tagging, the stipe length of plants from this stand ranged from 108 to $137 \mathrm{~cm}$, while their stipe diameter ranged from 23 to $31 \mathrm{~mm}$. In comparison, the 4.4-yr-old plants used in the age verification study ranged from 45 to $105 \mathrm{~cm}$ in stipe length and 17 to $35 \mathrm{~mm}$ in stipe diameter. Although there is little overlap in the stipe length ranges of these 2 stands of plants, the stipe diameter ranges are similar. Since it is growth in stipe diameter that ultimately determines whether more rings are added, we estimated the age of these plants at 5 yr when tagged, giving them an approximate age of 12 yr ( 5 yr estimated +7 yr tagged) when harvested. Based on these analyses, the estimated age by stipe ring counts of the larger plants were comparable to the approximate age of the stand.
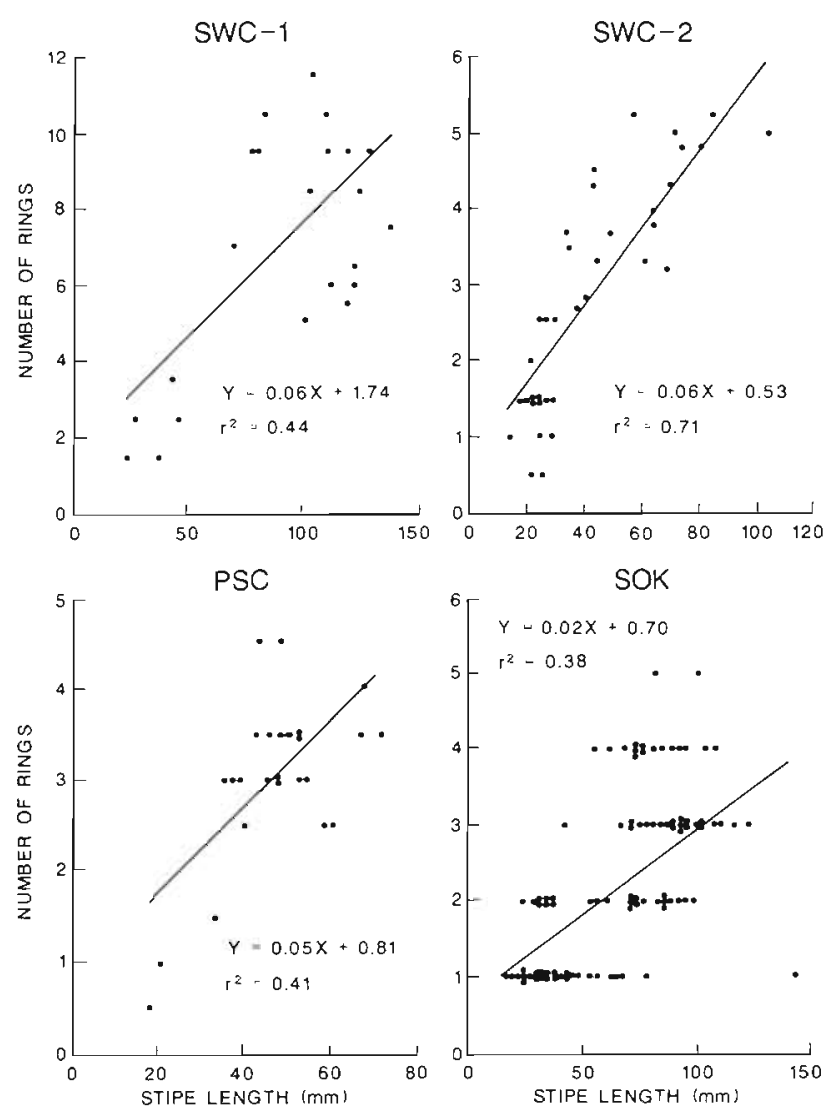

Fig. 4. Pterygophora californica. Relationship between number of rings and stipe length for 4 different stands. SWC. 1: Stillwater Cove stand with plants of unknown age; SWC-2 Stillwater Cove stand with plants of known age; PSC: Point Santa Cruz; SOK: San Onofre kelp forest. Overlapping points are vertically offset. See Fid. 2 for site locations

\section{Age determination using morphometric characteristics}

Stipe length and diameter were both positively correlated with the number of rings in all 4 of the stands examined (Figs. 4 and 5), and the overall relationship between each of these morphometric characteristics and ring number was significant (Table 1). Results from the ANCOVA indicate, however, that in general, both stipe length and diameter are poor predictors of age in Pterygophora californica. The relationship between stipe diameter and ring number differed significantly among stands (Table 1 ; also see Fig. 5). Second and more importantly, the relationship between ring number and either stipe length or diameter varied with stand. The significant length $x$ stand and diameter $x$ stand interactions in the analysis (Table 1) indicate the slopes of the regression lines for both morphometric variables differed significantly among stands (Figs. 4 and 5). Thus, accurate predictions of age based on these characteristics are stand-specific.
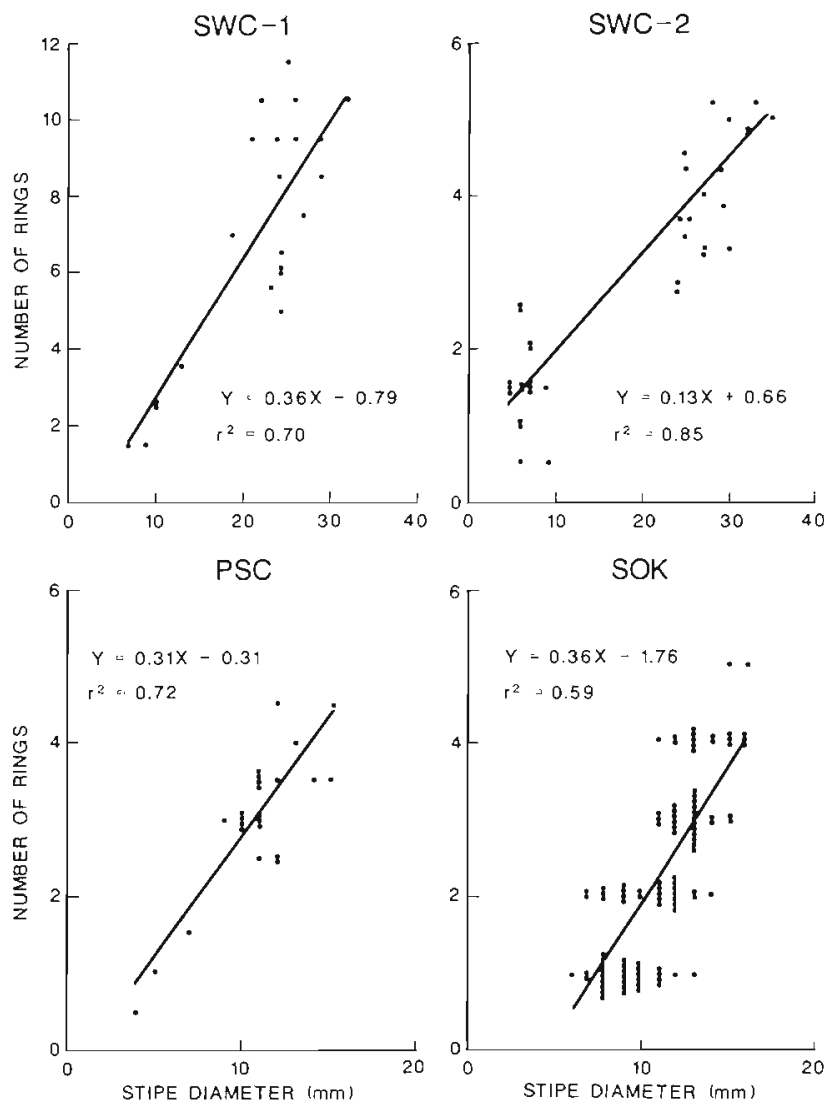

Fig. 5. Pterygophora californica. Relationship between number of rings and stipe diameter for 4 different stands. SWC-1: Stillwater Cove stand with plants of unknown age; SWC-2: Stillwater Cove stand with plants of known age: PSC: Point Sunta Crur; SOK: San Onofre kelp forest. Overlapping points are vertically offset. See Fig. 2 for site locations 
Table 1 Pterygophora californica. Results from the ANCOVA examining effect of stand on number of rings. The covariates are (a) stipe length and (b) stipe diameter

\begin{tabular}{|lrrrc|}
\hline (a) & & & & \\
Source of variation & DF & MS & F & $\mathrm{p}$ \\
\hline Length & 1 & 97.17 & 73.75 & 0.0001 \\
Stand & 3 & 1.12 & 0.85 & 0.4696 \\
Length $\times$ Stand & 3 & 11.00 & 8.36 & 0.0001 \\
Error & 176 & 1.31 & & \\
(b) & & & & \\
Source of variation & DF & MS & $F$ & $\mathrm{p}$ \\
\hline Diameter & 1 & 146.38 & 192.04 & 0.0001 \\
Stand & 3 & 6.35 & 8.34 & 0.0001 \\
Diameter $\times$ Stand & 3 & 23.01 & 30.20 & 0.0001 \\
Error & 176 & 0.76 & & \\
\hline
\end{tabular}

Within a stand, ring number appeared to be more closely correlated to stipe diameter than to stipe length (Figs. 4 and 5). Correlations between stipe length and ring number were generally low, suggesting that even within a stand, stipe length was a poor indicator of age.

\section{Environmental efîects}

At the start of both the density and light experiments the stipe dimensions of all experimental plants were not significantly different $(F=0.84, p>0.25$ for stipe length and $F=1.60, p>0.25$ for stipe diameter), and were normally distributed $\left(\chi^{2}=10.57, \mathrm{p}>0.10\right.$ for stipe length and $\chi^{2}=7.21, p>0.10$ for stipe diameter). Thus, the use of parametric statistics on uncorrected growth data was deemed appropriate, and any significant differences in stipe growth were attributed to events occurring over the course of the transplant experiments.

Growth in stipe length and diameter differed significantly between experimental density treatments (Table 2; $F=146.9, p<0.0005$ and $F=255.63$, $\mathrm{p}<0.0005$ respectively). Plants at high density grew faster in stipe length and slower in stipe diameter than plants at the medium or low density. Stipe growth of medium and low density plants did not differ significantly. In contrast, stand density appeared to have little influence on the stipe morphology of plants sampled from the 7 sites in the multi-site survey; there was little relationship between stand density and stipe length or diameter (Fig. 6). De Wreede (1984) used the ratio of mean stipe length/mean number of rings to determine if stipe elongation rates were similar between sites; for the 7 sites sampled in our multi-site survey these ratios varied from 10.1 to 31.0 .
Table 2. Pterygophora californica. Growth results of plants maintained at the various density levels for $22 \mathrm{wk}$. A 2-way nested ANOVA was used to test for significant differences in growth with 2 replicate racks nested within each density level, and 6 plants measured per rack. Data are means $\pm 95 \% \mathrm{CI}$ for all 12 plants at each density level. For both stipe length and stipe diameter, the medium and low density means were not significantly different from each other, but both were significantly different from the high density mean by Tukey multiple comparison test $(\mathrm{p} \leq 0.05)$

\begin{tabular}{|lccc|}
\hline & \multicolumn{3}{c}{ Density treatment levels } \\
& High & Medium & Low \\
\hline $\begin{array}{lccc}\text { Increase in stipe } \\
\text { length (cm) }\end{array}$ & $6.3 \pm 1.2$ & $4.4 \pm 0.8$ & $4.4 \pm 0.7$ \\
$\begin{array}{l}\text { Increase in stipe } \\
\text { diameter (mm) }\end{array}$ & $1.1 \pm 0.5$ & $2.0 \pm 0.6$ & $2.2 \pm 0.9$ \\
\hline
\end{tabular}
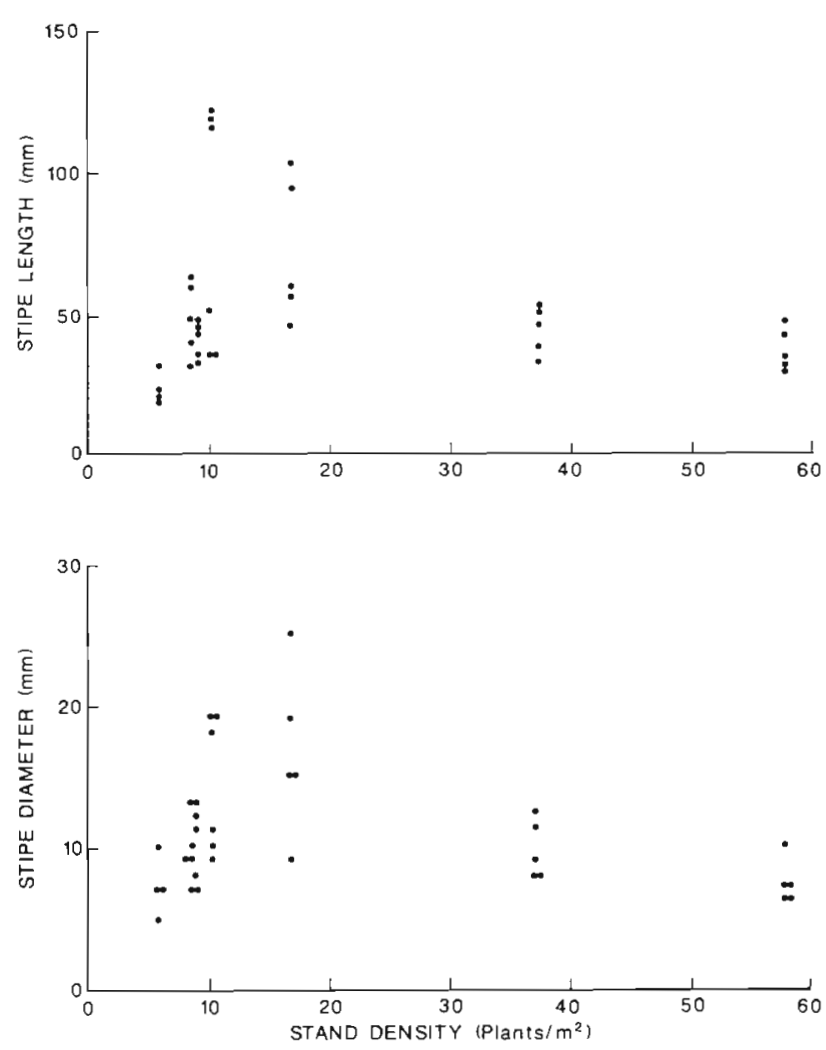

Fig. 6. Pterygophora californica. Relationship between stand density and stipe length and stipe diameter for plants collected in the multi-site survey. Overlapping points are horizontally offset. See Fig. 2 for site locations

Shades used in the light experiment effectively reduced the available light without increasing plant density. At the times of measurement, the average amount of light available under a canopy of adult Pterygophora californica was similar to the amount available under the shade treatment (Table 3). Likewise, the amount of light available to experimental plants 
under clear covers was similar to the amount available to plants in the open treatment (Table 3). On average, the available light under the clear covers was 2.7 times greater than that under the shades (Table 3). Thus, the clear covers mimicked the physical presence of shades without causing the same amount of light reduction. Even though light availability differed in the 3 light treatments, no significant differences in stipe growth were observed after $22 \mathrm{wk}$ (Table $3 ; \mathrm{F}=2.45, \mathrm{p}>0.25$ for stipe length and $F=6.54, p>0.05$ for stipe diameter).

\section{DISCUSSION}

The relationship between the number of rings and the known age of Pterygophora californica in a stand in Stillwater Cove suggests there is considerable variation among individuals. However, complete rings are generally produced annually in plants up to an age of $4 \mathrm{yr}$, and probably $12 \mathrm{yr}$. Although our results indicate estimating the age of cohorts by ring counts is valid, the accuracy of this method is questionable when used to estimate the age of an individual. Counts of the number of rings in plants of known age varied (95\% CI) by \pm $2 \mathrm{yr}$, and between readers by \pm 1 yr.

Results indicate plant age in Pterygophora californica cannot accurately be determined from measurements of stipe length. In general, correlations

Table 3. Pterygophora californica. Irradiance measured under natural adult canopies and the 3 light levels, and growth results of plants maintained under the various light levels for 22 wk. A 1-way fixed effects ANOVA was used to examine differences in irradiance levels (4 light levels with 4 measurements per light level). A 2-way nested ANOVA was used to examine the effects of the 3 experimental light levels on stipe growth with 2 replicate racks nested within each light level, and 6 plants measured on each rack. Irradiance data were means (range) passing through the canopy or light level. Stipe growth data are means $\pm 95 \% \mathrm{CI}$ of all experimental plants in each light levels. Irradiance under the adult canopy was not significantly different from shade, and clear was not significantly different from open, but under the adult canopy and shade were significantly different from clear and open by Tukey multiple comparison test $(p \leq 0.05)$. There were no significant differences in the amount of increase in stipe diameter or length among treatments (see text for details)

\begin{tabular}{|c|c|c|c|c|}
\hline & \multirow[t]{2}{*}{$\begin{array}{l}\text { Under } \\
\text { canopy }\end{array}$} & \multicolumn{3}{|c|}{$\begin{array}{l}\text { Expenmental light } \\
\text { treatment levels }\end{array}$} \\
\hline & & Shade & Clear & Open \\
\hline $\begin{array}{l}\% \text { Surface } \\
\text { irradiance }\end{array}$ & $\begin{array}{c}8.0 \\
(5.6-8.8)\end{array}$ & $\begin{array}{c}6.6 \\
(4.8-9.7)\end{array}$ & $\begin{array}{c}17.9 \\
(14.5-21.4)\end{array}$ & $\begin{array}{c}22.7 \\
(16.5-30.1)\end{array}$ \\
\hline $\begin{array}{l}\text { Increase in stipe } \\
\text { length }(\mathrm{cm})\end{array}$ & - & $5.1 \pm 1.0$ & $5.3 \pm 1.3$ & $4.2 \pm 0.8$ \\
\hline $\begin{array}{l}\text { Increase in stıpe } \\
\text { doômeter ( } \mathrm{mm})\end{array}$ & - & $1.6 \pm 0.5$ & $1.4 \pm 0.4$ & $2.0 \pm 0.6$ \\
\hline
\end{tabular}

between stipe length and number of cortical rings were low (Fig. 4). This indicates that there was substantial variability in stipe elongation between cohorts within a stand. Only if stipe elongation is predictable through time can it serve as an a priori method for estimating plant age. De Wreede (1984) found linear stipe elongation rates in 2 populations of $P$. californica from British Columbia. However, the stipe length to ring number ratios he calculated were smaller than those calculated for the 7 stands sampled in our multi-site survey, indicating slower rates of stipe elongation. This suggests any linear relationship between stipe length and ring number may be prolonged in plants from British Columbia. In contrast to the stands sampled by De Wreede (1984), all the stands sampled for this study occurred under surface canopies of Macrocystis pyrifera (Agardh) or Nereocystis luetkena (Mertens) for at least a portion of each year. The extent of these canopies can vary widely among sites and seasons (Foster \& Schiel 1985), and may impart effects that result in irregular growth patterns of understory kelps. Although it may be possible to age some populations of $P$. californica from stipe length measurements, it does not appear that this technique can be applied to plants occurring along the California coast.

The higher regression coefficients of stipe diameter versus ring number were expected since the same growth zone, the meristoderm, is responsible for increases in stipe diameter as well as ring number. However, the slopes and intercepts of the regressions varied among sites, suggesting the relationship between this morphometric measure and ring number is site-specific (Fig. 5; Table 1). These results indicate that, within a stand, prior information on the relationship between stipe diameter and ring number is necessary in order to estimate plant age from stipe diameter measurements alone.

Results of the density experiment showed that stipe growth of Pterygophora californica in Stillwater Cove is in part density-dependent, with high density plants growing faster in stipe length and slower in stipe diameter than their lower density counterparts. This pattern however, was not observed in the multi-site survey where stand density and stipe morphology were not correlated (Fig. 6). Factors other than stand density therefore, must also influence stipe morphology.

Terrestrial and marine plants growing at high density generally show increased rates of elongation compared to those of plants at lower density (Fang et al. 1962, Harper 1977, Schiel \& Choat 1980, Coyer \& Zaugg-Haglund 1982, Schiel 1985). This phenomenon is generally thought to be due to intraspecific competition for light (Fang et al. 1962, Harper 1977, Coyer \& Zaugg-Haglund 1982). Increased competition, however, that results in reduced irradiance negatively 
influences other aspects of growth (Kain 1979, Chapman \& Lindley 1980, Hutchings \& Budd 1981), and in Pterygophora californica may lead to reduced fitness (Reed 1989). In contrast, Schiel (1985) found that high densities of monospecific stands of Sargassum sinclarii (Hook et. Harv.) and Carpophyllum maschalocarpum (Tum.) resulted in greater growth and fecundity, but reduced survival. He suggested rapid increases in length may be detrimental to survival, leading to increased risks of storm dislodgement. Like other stipitate kelps (see Kain 1979 and Novaczek 1981) haptera number in $P$. californica appears to increase with stipe diameter (Hymanson pers obs.). Thus, the premature dislodgement of $P$. californica could be enhanced if increases in stipe diameter (and therefore haptera number) are reduced relative to increases in stipe length. Consequently, longer stiped plants are better competitors for light at high densities, but may suffer greater mortality during periods of high water motion.

If plant density affects growth in stipe width, then it must also affect ring and zone morphology, since the cells that form these structures determine the stipe diameter. Plant density could affect the rate at which tissue is deposited along the diameter and cause variation, particularly in the thickness of light zones (Fritts 1976). Inconsistent changes in stand density over time could result in rings and zones of variable size, further confounding the ability to estimate age.

Extended periods of reduced light resulting from neutral density screens did not significantly affect stipe growth of transplanted Pterygophora californica in Stillwater Cove. Lüning (1980) suggested at least $1 \%$ of the total surface irradiance is necessary for kelp growth. Experimental plants received well above this level (mean $=6.6 \%$ of the total surface irradiance), and most likely received enough light over the course of the experiment to negate treatment effects.

In an earlier study at Stillwater Cove, Reed \& Foster (1984) found that a dense canopy of Pterygophora californica significantly inhibited kelp recruitment. The density of $P$. californica in this earlier study was similar to that used in the light manipulation experiments $(7.4$ plants $\mathrm{m}^{-2}$ for this study, and 7.3 plants $\mathrm{m}^{-2}$ for Reed \& Foster's study). In the earlier study however, only 1 to $3 \%$ of the surface light passed through both the surface (Macrocystis pyrifera) and subsurface (Pterygophora californical canopies. Measurements made in this study showed that on average $8 \%$ of the surface light passed through the surface and subsurface canopies. The amount of light removed by a canopy is a function of plant size as well as individual density, suggesting density-dependent effects are not due to shear numbers alone.

It appears the constraints of estimating the age of Pterygophora californica are similar to those found in the methods for estimating the age of other organisms including the kelp Laminaria setchellii (Klinger \& De Wreede 1988): individual and population variability prevents the use of some morphometric measures (e.g. stipe length) to estimate age, and require site-specific calibration for the use of others (e.g. stipe diameter). As found in this study, such variation may also confound the relationship between age and structures that periodically but regularly vary in morphology (e.g. cortical rings). Yet in spite of natural variation, our results and those of De Wreede (1984) show that cortical rings can be used to determine the age structure of $P$. californica populations. Combining this with an understanding of the relationship between density, environment, and morphology should prove helpful when examining processes that structure kelp populations.

Acknowledgements. The authors thank D. Schiel for his help in all phases of this study. We are grateful for the helpful comments on earlier versions of this manuscript by $\mathrm{G}$. Cailliet. R. De Wreede, J. Bence, R. Ambrose, and J Pearse. The first author is grateful to a number of fellow students at Moss Landing Marine Laboratories who served as dive buddies during the course of the density and light experiments. Portions of this study were funded by a Kim Peppard Memorial Scholarship, and a David and Lucile Packard Foundation grant for which the first author is grateful.

\section{LITERATURE CITED}

Abbott, I. A., Hollenberg, G. J. (1976). Marine algae of California. Stanford University Press, Stanford, California

Bazzaz, F. A. (1983). Characteristics of populations in relation to disturbance in natural and man-modified ecosystems. In: Mooney, H. A., Godron, M. (eds.) Disturbance and ecosystems: components of response. Springer-Verlag, Berlin, p. 259-275

Cailliet, G. M., Love, M. S., Ebeling, A. W. (1986). Fishes: a field and laboratory manual on their structure, identification, and natural history. Wadsworth Publishing Co., Belmont, California

Canestro, D. C. (1987). The effects of the adult canopy on the growth and survivorship of Pterygophora californica in a central Calífornia kelp forest. Masters thesis, San Jose State University, California

Canham, C. D., Marks, P. L. (1985). The response of woody plants to disturbance: patterns of establishment and growth. In: Pickett, S. T A., White, P. S. (eds.) The ecology of natural disturbance and patch dynamics. Academic Press, New York, p. 197-216

Chapman, A. R. O., Lindley, J. E. (1980). Seasonal growth of Laminaria solidungula in the Canadian high arctic in relation to irradiance and dissolved nutrient concentrations. Mar. Biol. 57. 1-5

Connell, J. H., Sousa, W. P. (1983). On the evidence needed to judge ecological stability or persistence. Am. Nat. 121 $789-824$

Coyer, J. A, Zaugg-Haglund, A. C. (1982). A demographic study of the elk kelp Pelagophycus porra (Laminariales Lessoniacedel with notes on Pelagophycus $\times$ Macrocystis hybrids. Phycologia 21. 400-407 
Dawson, E. Y., Foster, M. S. (1982). Seashore plants of California. University of California Press, Berkeley

Dayton, P. K., Currie, V., Gerrodette, T., Keller, D., Rosenthal, R. Ven Tresca, D. (1984). Patch dynamics and stability of some California kelp communities. Ecol Monogr. 54: 253-289

Dean, I A., Jacobsen, F. R. (1984). Growth of juvenile Macrocystis pyrifera (Laminariales) in relation to environmental factors. Mar Biol. 83: 301-311

Dean, T. A., Schroeter, S. C., Dixon, J. D. (1984). Effects of grazing by two species of sea urchins (Strongylocentrotus franciscanus and Lytechinus anamesus) on recruitment and survival of two species of kelp (Macrocystis pyrifera and Pterygophora callfornica). Mar Biol. 78: 301-313

De Wreede, R. E. (1984). Growth and age class distribution of Pterygophora californica (Phaeophyta). Mar Ecol. Prog. Ser 19: 93-100

De Wreede, R. E. (1986). Demographic characteristics of Pterygophora californica (Laminariales, Phaeophyta). Phycologia. 25: 11-17

Druehl, L. D. (1981). Geographical distribution. In: Lobban, C. S., Wynne, M. J. (eds.) The biology of seaweeds. University of California Press, Berkeley, p. 306-325

Ebert, T. A. (1988). Calibration of natural growth lines in ossicles of two sea urchins, Strogylocentrotus purpuratus and Echinometra mathaei, using tetracycline. In: Burke, R. D., Mladenov, P. V., Lambert, P., Parsley, R. (eds.) Echinoderm biology. A. A. Balkema, Rotterdam, p. $435-443$

Ekaratne, S. U. K., Crisp, D. J. (1982). Tidal micro-growth bands in intertidal gastropod shells, with an evaluation of band-dating techniques. Proc. R. Soc. Lond. Ser. B 214: $305-323$

Fang, T. C., Jiang, B. Y., Li, J. J. (1962). On the inheritance of stipe length in Haidai (Laminaria japonica Aresch). Acta. Bot. Sin. 10: 327-335

Foster, M. S. (1982). The regulation of macroalgal associations in kelp forest.s. In: Srivastava, L. (ed.) Synthetic and degradative processes in marine macrophytes. Walter de Gruyter \& Co., Berlin, p. 185-205

Foster, M. S., Schiel, D. R. (1985). The ecology of giant kelp forests in California: a community profile. U.S. Fish Wildl Serv. Biol. Rep. 85 (7.2) 152 pp.

Fritts, H. (1976). Tree rings and climate. Academic Press, New York

Frye, T. C. (1918). The age of Pterygophora californica. Publs Puget Sound mar. Biol. Stn 2: 65-71

Harper, J. L. (1977). Population biology of plants. Academic Press, New York

Hayashiada, F. (1977). On age and growth of a brown alga Ecklonia cava Kjellman, forming aquatic forests. Bull. Jap Soc. scient. Fish. 43: 1043-1051

Hutchings, M. J., Budd, C. S. J. (1981). Plant self-thinning and leaf area dynamics in experimental and natural monocultures. Oikos 36: 319-325

Hymanson, Z. P. (1986). The effects of density and light availability on the stipe morphology of Pterygophora californica. Masters thesis. San Francisco State University. San Francisco, California

This article was submitted to the editor
John, D. M. (1969). Ecological study of Lammaria ochroleuca. J. mar biol. Ass. U. K. 49: 175-187

Kain, J. M. (1963). Aspects of the biology of Laminaria hyperborea II. Age, weight, and length. J. mar biol. Ass. U. K. 43: 129-151

Kain, J. M. (1979). A view of the genus Laminaria. Oceanogr mar. biol. A. Rev. 17: 101-161

Klinger, T., De Wreede, R. E. (1988). Stipe rings, age and size in populations of Laminaria setchellii (Laminarilaes. Phaeophyta) in British Columbia, Canada. Phycologia 27: $234-240$

Lobban, C. S. (1978). The growth and death of the Macrocystis sporophyte (Phaeophyceae, Laminariales). Phycologia 17: 196-212

Lüning, K. (1980). Photobiology of seaweeds: ecophysical aspects. In: Levring, $T$ (ed.) Proc. Xth Int. Seaweed Symposium. Walter de Gruyter \& Co., Berlin p. 35-56

Mac Millian, C. (1902). XLI. Observations on Pterygophora. Minn. Bot. Stud. 2: 723-741

Morris, P. A. (1972). A review of mammalian age determination methods. Mammal Rev. 2: 69-104

Novaczek, I. (1981). Stipe growth rings in Ecklonia radiata (C. A. G.) J. A. G. (Laminariales). Br Phycol. J. 16 363-371

Parke, M. (1948). Studies on British Laminariaceae. I. Growth in Laminaria saccharina (L) Lamour. J. mar. biol. Ass. U. K 27: $651-708$

Pearse, J.S., Hines, A. H. (1979). Expansion of a central California kelp forest following the mass mortality of sea urchins. Mar. Biol. 51. 83-91

Pickett, S. T. A., White, P. S. (eds.) (1985). The ecology of natural disturbance and patch dynamics. Academic Press, New York

Reed, D. C. (1989). Patterns, mechanisms, and consequencs of variation in brown algal dispersal and recruitment. Ph. D. dissertation, University of California, Santa Barbara

Reed, D. C., Foster, M. S. (1984). The effects of canopy shading on algal recruitment and growth in a giant kelp forest. Ecology 65: 937-948

Rigg, B. G., Miller, R. C. (1949). Intertidal plant and animal zonation in the vicinity of Neah Bay, Washington, Proc Calif. Acad. Sci. 26: 323-351

SAS Institute (1985). SAS/STAT guide for personal computers, 6th edn. SAS Institute Inc., Cary, North Carolina

Schiel, D. R. (1985). Growth, survival and reproduction of two species of marine algae at different densities in natural stands. J. Ecol. 73: 199-217

Schiel, D. R., Choat, J. H. (1980). Effects of density on monospecific stands of marine algae. Nature, Lond. 285: 324-326

Smith, A. I. (1939). The comparative histology of some of the Laminariales. Am. J. Bot. 26: 571-585

Sokal, R. R., Rohlf, R. J. (1981). Biometry, 2nd edn. W. H. Freeman \& Co., San Francisco

Sousa, W. P. (1984). The role of disturbance in natural communities. Ann. Rev. Ecol. Syst. 15: 353-391

Veblen, T. T. (1985). Stand dynamics in Chilean Nothofagus forests. In: Pickett, S. T A., White, P. S. (eds.) The ecology of natural disturbance and patch dynamics. Academic Press, New York, p. 35-51

Manuscript first received: June 19, 1989

Revised version accepted: October 3, 1989 